\title{
Accurate Normalization Factor for Wire Myography of Rat Femoral Artery
}

\author{
P. SLEZÁK ${ }^{1}$, I. WACZULÍKOVÁ ${ }^{2}$, P. BALIŠ ${ }^{1}$, A. PÚZSEROVÁ ${ }^{1}$ \\ ${ }^{1}$ Institute of Normal and Pathological Physiology, Slovak Academy of Sciences, Bratislava, Slovak \\ Republic, ${ }^{2}$ Division of Biomedical Physics, Faculty of Mathematics, Physics and Informatics, \\ Comenius University, Bratislava, Slovak Republic
}

Received June 10, 2010

Accepted September 20, 2010

\begin{abstract}
Summary
Wire myograph is a device for the in vitro investigation of both, active and passive properties of arteries. Arteries from a variety of animal species, pathological states, and vascular beds were investigated using this method. We focus on the normalization procedure which is aimed to standardize experimental settings and, in part, to simulate physiological conditions. During normalization, it is determined the internal circumference of a vessel stretched to a tension that corresponds to the transmural pressure of $100 \mathrm{~mm} \mathrm{Hg}$ (IC100). Once it is determined, the internal circumference is traditionally set to (0.9.IC100). However, this constant 0.9 , called also the normalization factor (NF), was experimentally determined for rat small mesenteric arteries only. Therefore, the aim of our work was to show the influence of different NFs on the passive tension and reactivity of both, rat femoral arteries (FA) and the first branches of superior mesenteric arteries (MA). We found out that the maximal active wall tension of the FA was achieved at the NF value of 1.1, and that of the MA at 0.9. Considering the values of the active wall tension we suggest that higher reactivity and better signal-tonoise ratio in FA can be achieved when the NF is set at least to 1.0 .
\end{abstract}

\section{Key words}

Wire myograph • Normalization procedure • Rat femoral artery

\section{Corresponding author}

P. Slezák, Institute of Normal and Pathological Physiology, Slovak Academy of Sciences, Sienkiewiczova 1, 81371 Bratislava, Slovak Republic. Fax: +421-2-52968516. E-mail: peter.slezak5@ gmail.com, peter.slezak@savba.sk
A wire myograph is a device developed by Mulvany and Halpern (1977) for the in vitro investigation of both, active and passive properties of the arteries with the diameters between 100 and $1000 \mu \mathrm{m}$ (Mulvany 2004). Blood vessels from a variety of arteries: femoral, caudal, mesenteric, pulmonary, carotid, and aorta (Púzserová et al. 2007, Khazaei et al. 2008, Bal et al. 2009, Žaloudíková et al. 2009) from rats and other species in both, physiological and pathological states, have been studied with this technique (Spiers and Padmanabhan 2005).

The myograph measurement consists of the following steps: preparation and mounting of the arteries, normalization, assessment of tissue viability, and construction of a cumulative concentration response curve (Spiers and Padmanabhan 2005). In the present communication we have focused on the normalization procedure which ensures the standardization of the experimental conditions (Lew and McPherson 1996) and reliable assessment of the physiological responses of the vessel (Spiers and Padmanabhan 2005). When comparing the vascular reactivity of vasoactive drugs, the results depend, to some extent, on the initial passive condition (the initial resting tension under which vessels are placed) (McPherson 1992). Moreover, the active response of a vessel depends on the extent of stretch (according to the active tension/internal circumference relationship), which makes it important to set vessels to such internal circumference that yields the maximal response (Mulvany 2004). Another goal of normalization is to mimic the in vivo conditions, which may be of 
importance in pathophysiological studies concerning e.g. hypertension. In such studies, the experimental design should consider the target pressure and NF dependently on the arterial types and species.

The normalization determines the internal circumference that a vessel would have when relaxed under a transmural pressure of $100 \mathrm{~mm} \mathrm{Hg}$ (IC100) (Mulvany 2004). This is performed by a gradual distending of the artery and by recording the sets of micrometer and force readings. The recorded data are then transformed to the internal circumference - pressure data and fitted with an exponential curve (Davis and Gore 1989). In the next step, the Laplace's equation is used to determine the point on the exponential curve, which corresponds to $100 \mathrm{~mm} \mathrm{Hg}$. Traditionally, the internal circumference is then set to $\mathrm{IC} 1=0.9 \cdot \mathrm{IC} 100$, which should yield the maximal active wall tension. This was shown to hold for (at least) rat small mesenteric arteries (Mulvany and Nyborg 1980, Mulvany 2004). The constant 0.9 can be called the normalization factor (NF). However, it is not clear whether this NF value is also optimal for other vessels (Van den Akker et al. 2010). Because setting the artery to a condition, at which it produces maximal active tension, enhances resolution of this technique (optimizes signal-to-noise ratio, $\mathrm{S} / \mathrm{N}$ ), it is desirable to check whether the reported value can be used also for other types of arteries. (Note: $\mathrm{S} / \mathrm{N}$ is a measure of how much a signal has been corrupted by noise. It is always used within the context of a given experimental design.) Therefore, we examined the passive and active wall tensions, for the first branches of the superior mesenteric arteries and for rat femoral arteries, developed at different NF values.

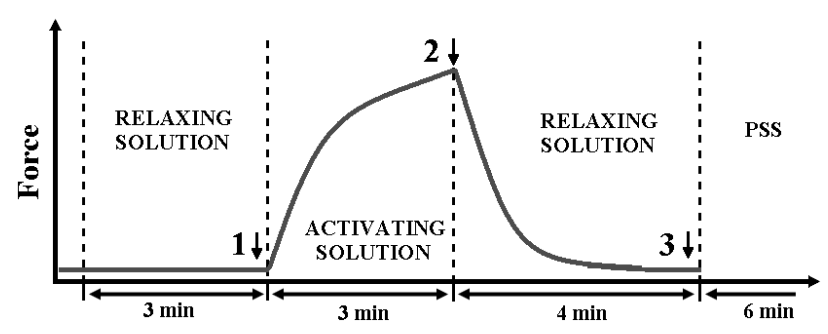

Fig. 1. Schema of the experimental protocol. At each setting the arteries were first relaxed in a relaxing solution for $3 \mathrm{~min}$, then activated with an activating solution for $3 \mathrm{~min}$, and then again relaxed in the relaxing solution for 4 min. Finally, the vessel was equilibrated for $6 \mathrm{~min}$ in PSS. Passive tension was determined as a mean of the tensions determined at points 1 and 3. Active tension was determined as the difference between the maximal tension of the vessel in the activating solution (point 2) and the passive tension.
Experimental protocol. Physiological salt solution (PSS) contained (in $\mathrm{mM}$ ): $\mathrm{NaCl}, 118.99$; $\mathrm{NaHCO}_{3}, 25 ; \mathrm{KCl}, 4.69 ; \mathrm{KH}_{2} \mathrm{PO}_{4}, 1.18 ; \mathrm{MgSO}_{4}, 1.17$; $\mathrm{CaCl}_{2}, 2.5$; ethylenediaminetetraacetic acid disodium salt dihydrate (EDTA), 0.03; glucose, 5.5. Activating solution was as for PSS, but with $40 \mu \mathrm{M}$ norepinephrine, with an equimolar replaced $\mathrm{NaCl}$ by $\mathrm{KCl}$ and with $2.5 \mathrm{mM}$ $\mathrm{CaCl}_{2} \cdot 2 \mathrm{H}_{2} \mathrm{O}$. Relaxing solution was as for PSS but without $\mathrm{CaCl}_{2}$ and with $1 \mathrm{mM}$ ethyleneglycol-bis- $(\beta-$ aminoethyl ether)-N, N, N', N'-tetraacetic acid (EGTA). All solutions were bubbled with $95 \% \mathrm{O}_{2}$ and $5 \% \mathrm{CO}_{2}$ mixture and adjusted to $\mathrm{pH}$ 7.4.

The femoral arteries and the first branches of the superior mesenteric arteries obtained from 12 week-old male healthy Wistar rats (body weight $261 \pm 6 \mathrm{~g}, \mathrm{n}=10$ ) were investigated using the wire myograph (Mulvany and Halpern 1977). The experiments were performed in accordance with the European Community and NIH guidelines for use of experimental animals as well as with the rules issued by the State Veterinary and Food Administration of the Slovak Republic, based on \$37(6), of the Act No. 488/2002 Coll. The rats were anesthetized by thiopental $(60 \mathrm{mg} / \mathrm{kg})$ with heparin. After cervical dislocation, the arteries were carefully dissected, immersed and transferred to PSS without $\mathrm{CaCl}_{2}$, and then cleaned to remove the adipose and connective tissues. Arterial segments (approximately $1.5 \mathrm{~mm}$ long) were mounted in a small vessel wire myograph (Dual Wire Myograph System 410A, DMT A/S, Aarhus, Denmark) using $40 \mu \mathrm{m}$ wires and were stabilized for $30 \mathrm{~min}$. Then the normalized inner diameter corresponding to $13.3 \mathrm{kPa}$ $(100 \mathrm{~mm} \mathrm{Hg})$ was determined in PSS containing $\mathrm{CaCl}_{2}$. The PSS in the myograph chamber was exchanged immediately after normalization, and the arteries were left to stabilize for another $30 \mathrm{~min}$. After this stabilization period, the PSS was exchanged for the relaxing solution for $3 \mathrm{~min}$ (point 1), the vessels were activated with the activating solution for $3 \mathrm{~min}$ (point 2), and finally relaxed again in the relaxing solution for 4 min (point 3); see Figure 1. At the end, the arteries were equilibrated in PSS for $6 \mathrm{~min}$. Passive tension was determined as a mean of the tensions at points 1 and 3 (Fig. 1). The difference between the maximal tension of the vessel in the activating solution (point 2) and the passive tension was taken as active tension. Thereafter the protocol was repeated with a different NF value which was adjusted to a new value at the start of the equilibration period in PSS. The order of the NF values was pseudo-randomly determined from the following set of values: 0.7, 0.8, 0.9, 
Table 1. Normalization factor (NF) and the respective passive wall tension, active wall tension, and inner diameter for both, femoral artery and the first branch of the superior mesenteric artery.

\begin{tabular}{|c|c|c|c|c|c|c|c|c|}
\hline \multirow[b]{2}{*}{ NF } & \multirow[b]{2}{*}{$\mathbf{n}$} & \multicolumn{3}{|c|}{ Femoral artery } & \multicolumn{4}{|c|}{ First branch of the superior mesenteric artery } \\
\hline & & $\begin{array}{c}\text { passive wall } \\
\text { tension } \\
(\mathrm{mN} / \mathrm{mm})\end{array}$ & $\begin{array}{c}\text { active wall } \\
\text { tension } \\
(\mathrm{mN} / \mathrm{mm})\end{array}$ & $\begin{array}{c}\text { inner } \\
\text { diameter } \\
(\mu \mathrm{m})\end{array}$ & $\mathbf{n}$ & $\begin{array}{c}\text { passive wall } \\
\text { tension } \\
(\mathrm{mN} / \mathrm{mm})\end{array}$ & $\begin{array}{c}\text { active wall } \\
\text { tension } \\
(\mathrm{mN} / \mathrm{mm})\end{array}$ & $\begin{array}{c}\text { inner } \\
\text { diameter } \\
(\mu \mathrm{m})\end{array}$ \\
\hline 0.7 & 4 & $0.19 \pm 0.01$ & $2.70 \pm 0.36$ & $359.6 \pm 34.4$ & 4 & $0.36 \pm 0.08$ & $3.59 \pm 0.09$ & $246.3 \pm 15.1$ \\
\hline 0.8 & 5 & $0.24 \pm 0.06$ & $3.48 \pm 0.51$ & $411.3 \pm 31.9$ & 9 & $0.57 \pm 0.03$ & $4.14 \pm 0.31$ & $271.9 \pm 9.53$ \\
\hline 0.9 & 10 & $0.48 \pm 0.12$ & $4.69 \pm 0.38$ & $485.7 \pm 23.7$ & 9 & $0.92 \pm 0.05$ & $4.23 \pm 0.45$ & $297.7 \pm 10.7$ \\
\hline 1.0 & 10 & $0.96 \pm 0.18$ & $4.95 \pm 0.39$ & $539.2 \pm 26.4$ & 9 & $1.38 \pm 0.06$ & $3.94 \pm 0.23$ & $330.1 \pm 11.9$ \\
\hline 1.1 & 10 & $1.47 \pm 0.27$ & $5.19 \pm 0.38$ & $579.1 \pm 28.9$ & 9 & $2.13 \pm 0.07$ & $3.61 \pm 0.28$ & $349.3 \pm 13.1$ \\
\hline 1.2 & 10 & $2.24 \pm 0.40$ & $5.07 \pm 0.40$ & $625.8 \pm 31.6$ & 4 & $3.96 \pm 0.10$ & $2.65 \pm 0.86$ & $388.7 \pm 20.2$ \\
\hline 1.4 & 5 & $4.26 \pm 0.70$ & $4.57 \pm 0.53$ & $727.9 \pm 19.8$ & - & - & - & - \\
\hline
\end{tabular}

Data are presented as mean \pm S.E.M., and $n$ denotes the number of independent measurements.

1.1, 1.2, and 1.4. The protocol was adopted with a little modification from Mulvany and Warshav (1979). The experiments were performed at $37^{\circ} \mathrm{C}$.

The normalization factor and respective passive wall tension, active wall tension, and inner diameter for both, femoral artery and the first branch of the superior mesenteric artery, are presented in Table 1 . We found that for the first branches of the rat superior mesenteric arteries, the maximal active wall tension was developed at the NF value of about 0.9. In the rat femoral arteries, the maximal active wall tension was achieved at the NF value of 1.1. In these arteries, the passive wall tension amounted to about $9 \%, 16 \%, 22 \%$, and $31 \%$ of the whole wall tension value, when the NF was set to values of $0.9,1.0,1.1$, and 1.2 , respectively. The signal-to-noise ratio calculated as a mean of the active wall tension data (signal) divided by its standard deviation (noise) was improved by $10 \%$ at $\mathrm{NF}$ value of $1.1(\mathrm{~S} / \mathrm{N}=4.3)$ in comparison with that at $\mathrm{NF}$ value of $0.9(\mathrm{~S} / \mathrm{N}=3.9)$.

We showed that setting the femoral arteries to a circumference corrected by NF of at least 1.0 provides higher active tension development and better signal-tonoise ratio than at the commonly used NF value of 0.9 .

\section{Conflict of Interest}

There is no conflict of interest.

\section{Acknowledgements}

This study was supported by the Science and Technology Assistance Agency, grant No. APVT-51-018004, and by the Slovak Grant Agency for Science, grants No. 2/0084/10 and No. 2/0173/08, and FUSION grant No. FU06-CT-2006-0441.

\section{References}

BAL MS, PAULIS L, ZICHA J, KUNEŠ J: Effect of protein kinase C and protein kinase A inhibitors on contraction of isolated femoral arteries of SHR and Wistar rats. Physiol Res 58: 793-798, 2009.

DAVIS MJ, GORE RW: Length-tension relationship of vascular smooth muscle in single arterioles. Am J Physiol 256: H630-H640, 1989.

KHAZAEI M, MOIEN-AFSHARI F, KIEFFER TJ, LAHER I: Effect of exercise on augmented aortic vasoconstriction in the $\mathrm{db} / \mathrm{db}$ mouse model of type-II diabetes. Physiol Res 57: 847-856, 2008.

LEW MJ, MCPHERSON GA: Isolated tissue techniques. In: The Pharmacology of Vascular Smooth Muscle. CJ GARLAND, JA ANGUS (eds), Oxford University Press, Oxford, 1996, pp 25-41.

MCPHERSON GA: Assessing vascular reactivity of arteries in the small vessel myograph. Clin Exp Pharmacol Physiol 19: 815-825, 1992.

MULVANY MJ: Procedures for investigation of small vessels using small vessel myograph. Danish Myo Technology, 2004. Retrieved from http://www.dmt.dk/files/manualer/procedures_for_investigation.pdf (August 24, 2010) 
MULVANY MJ, HALPERN W: Contractile properties of small arterial resistance vessels in spontaneously hypertensive and normotensive rats. Circ Res 41: 19-26, 1977.

MULVANY MJ, NYBORG N: An increased calcium sensitivity of mesenteric resistance vessels in young and adult spontaneously hypertensive rats. Br J Pharmacol 71: 585-596, 1980.

MULVANY MJ, WARSHAW DM: The active tension-length curve of vascular smooth muscle related to its cellular components. J Gen Physiol 74: 85-104, 1979.

PÚZSEROVÁ A, CSIZMADIOVÁ Z, BERNÁTOVÁ I: Effect of blood pressure on L-NAME-sensitive component of vasorelaxation in adult rats. Physiol Res 56 (Suppl 2): S77-S84, 2007.

SPIERS A, PADMANABHAN N: A quide to wire myography. In: Hypertension Methods and Protocols. JP FENNELL, AH BAKER (eds), Humana Press, New Jersey, 2005, pp 91-104.

VAN DEN AKKER J, SCHOORL MJC, BAKKER ENTP, VAN BAVEL E: Small artery remodeling: current concepts and questions. $J$ Vasc Res 47: 183-202, 2010.

ŽALOUDÍKOVÁ M, VÍZEK M, HERGET J: Hyperoxia blunts acute hypoxia- and PGF $2 \alpha$-induced pulmonary vasoconstriction in chronically hypoxic rats. Physiol Res 58: 917-920, 2009. 